\title{
Trusting Our Selves to Technology
}

\author{
Asle H. Kiran • Peter-Paul Verbeek
}

Received: 28 June 2010 / Accepted: 12 August 2010 /Published online: 24 September 2010

(C) The Author(s) 2010. This article is published with open access at Springerlink.com

\begin{abstract}
Trust is a central dimension in the relation between human beings and technologies. In many discourses about technology, the relation between human beings and technologies is conceptualized as an external relation: a relation between pre-given entities that can have an impact on each other but that do not mutually constitute each other. From this perspective, relations of trust can vary between reliance, as is present for instance in technological extensionism, and suspicion, as in various precautionary approaches in ethics that focus on technological risks. Against these two interpretations of trust, this article develops a third one. Based on a more internal account of the relations between human beings and technologies, it becomes possible to see that every technological development puts at stake what it means to be a human being. Using technologies, then, implies trusting ourselves to technologies. We argue that this does not imply an uncritical subjection to technology. Rather, recognizing that technologies help to constitute human subjectivity implies that human beings can get actively involved in processes of technological mediation. Trust then has the character of confidence: deliberately trusting oneself to technology
\end{abstract}

Keywords Trust $\cdot$ Technology $\cdot$ Mediation

\section{Introduction: Trust, Reliance, and Suspicion}

Both implicitly and explicitly, trust has always been a central issue in philosophical approaches to and ethical evaluations of technology, ranging from issues of safety and reliability to analyses of risk and the development of a precautionary principle.

\footnotetext{
A. H. Kiran $(\bowtie) \cdot$ P.-P. Verbeek

Department of Philosophy, University of Twente, Enschede, Netherlands

e-mail: A.H.Kiran@gw.utwente.nl

P.-P. Verbeek

e-mail: p.p.c.c.verbeek@utwente.nl

P.-P. Verbeek

Department of Philosophy, Delft University of Technology, Delft, The Netherlands
} 
In the continental tradition, for example, Heidegger's analysis of "the tool" emphasized the importance of its reliability. Tools can only be used for doing something when they are trustworthy - even to the extent that we do not experience them explicitly when we deal with them, but engage with the world through them. Most well-known here are Heidegger's analysis of the workshop in Being and Time (Heidegger 1962) and his analysis of equipment in The Origin of the Work of Art (Heidegger 1977a). Heidegger's central claim in both analyses is that a proper understanding of tools and equipment requires us to approach them as part of the relations between human beings and the world in which they live. We cannot understand what a hammer is, or a pair of shoes, by describing their properties, but only by describing how they are present when we use them. Moreover, in situations of use, they typically withdraw from our attention. We can only use them if we can rely on them - if not; we need to pay attention to the things themselves, rather than to what we can do with them.

Current discussions about human enhancement can serve as a second, yet entirely different, example of the role of trust in discussions about technology. In the socalled transhumanist approach, technology is explicitly trusted to enhance substantially our bodily and mental capacities, even to the point that we should consider our current condition as poor and outdated. In this view, the possibility that implants, drugs, and genetic selection and modification have to enhance the human being is trusted as a reliable starting point for making the moral claim that we should head toward a posthuman future.

At the same time, though, distrust has always played an important role in the philosophy and ethics of technology as well (Heidegger 1977b; Ellul 1964; Jaspers 1959). To start with the continental tradition again: in his later works, Martin Heidegger developed his still influential approach to technology, analyzing it as "the supreme danger" because it would ultimately make us unable to interpret reality in other terms than as a set of raw materials (Heidegger 1977b). Considering technologies as instruments, that we can simply use for good and bad things, leads us astray, because it overlooks the fundamental rootedness of technology in a specific, technological mode of thinking. This mode of thinking is for Heidegger "the highest danger" because it obstructs other modes of thinking: every premeditated attempt to find a way out of manipulative thinking reinforces the will to manipulation.

But also various approaches in contemporary ethics of technology have a strong basis in distrust, because of the central role risk plays in them (Fukuyama 2002; Habermas 2003; Asveld and Roeser 2008; Hansson 2009). Technologies can impose risks on individuals and on society, ranging from health risks to terrorist abuse and from environmental impacts to social inequality. In these approaches, the task of philosophers and ethicists of technology is often taken to be to theorize the various manifestations and understandings of risk and to develop frameworks for dealing with risks in responsible ways (Hansson 2009). In some approaches to the ethics of technology, this basic form of distrust was even the basis for developing the socalled "precautionary principle", for which avoiding the risk of undesirable consequences is the central ethical criterion (Jonas 1984).

In this article, we will investigate and expand the notion of trust in philosophy of technology. We will develop an alternative approach to trust, considering it a central 
dimension in the relations between human beings and technologies. In the approaches to trust mentioned above, ranging from 'reliability' to 'suspicion', the concepts of trust is understood in terms of a distinct separation of human beings and technologies. Technologies find themselves in a different domain than human beings, and trust is needed when the technological domain might become a threat on the human domain. Only in trusted situations can technologies be allowed to enter the human realm, while it needs to be kept out in situations of distrust. Humanity has either to be protected against technology, as the precautionary principle has it, or to abandon itself to technology, as the transhumanists propose.

Our claim is that this is a "false dilemma"; the consequence of a metaphysical framework in which subjects (humans) and objects (technologies) are taken as two fundamentally distinct - and opposed - ontological categories (cf. Latour 1993). On such a view, the relation between humans and technologies is seen as an external relation, in which the two can interact but are not intrinsically connected. By approaching this relation as 'external', however, the intricate, and intimate, connections between the two remain underexposed. Against this external orientation, therefore, we will develop an 'internal' account of the relation between human beings and technology. Rather than focusing on reliability or a lack thereof, we will focus on confidence as a different meaning of trust in technology. And against the question if we should trust technology, we will investigate what it could mean to trust ourselves to technology.

We shall develop our argument in two steps. First, we will analyze the widespread conceptualization of technology as an extension of the human being. This analysis will expose a variety of reasons why the external account is untenable. Criticizing technological extensionism brings out in plain view both the main assumptions of the external account and the weaknesses in regarding humans and technologies as two ontologically distinct categories. We will substantiate the conceptual analysis with two examples of technological extensions, each pertaining to a different configuration of the relation between human beings and technologies. One, we will discuss telemonitoring applications, which play an increasingly big role in healthcare. Such devices enable people to monitor the status of their heart beat, blood pressure, muscle tension, et cetera, and have important implications that relate to the theme of trust. People rely on them, after all, and regain an important part of their autonomy because they do not need to be hospitalized. And two, we will discuss prosthetics, in relation to the so-called field of "human enhancement technology". Both examples will show the limitations of the extensionist idea and of the notion of trust embodied in it.

In the second step of our argument, we will elaborate a notion of trust that moves beyond the flaws and shortcomings in this external depiction of the relation between humans and technologies. How should we understand the manner in which we can and do trust technologies, beyond merely relying on their functioning or fearing the risks they impose upon us? Conceptualizing the 'internal' character of the relations between humans and technologies will make it possible to develop a different conceptualization of trust as well. Rather than being able to rely on technology, or to be suspicious of it, the intricate connections between humanity and technology urge us to develop the ability to actively trust ourselves to technology. As we will argue, while being a product of technological mediations, human beings also have the 
ability to find a relation to those mediations. This complex interplay between mediation and self-constitution is the configuration in which the relations between trust and technology need to be understood.

\section{Technological Extensionism}

\subsection{The Extensionist Idea}

The idea of extending the human being with technologies could be seen as the most obvious and widespread conceptualization of the relation between human beings and technologies. Central to this extensionist idea is a specific form of trust in technology; human beings can rely on technology to extend the human being in adequate ways. As we shall see later, understanding the basic function of technologies as strengthening or replacing the body or parts of the body has always been a familiar thought in the history of thinking about technology. Today, this idea lives on in new electronic gadgets that are designed as if they were extensions of our bodies (Clark 2003), and in fantasies about enhancement technologies such as exoskeletons and sensory augmentation. ${ }^{1}$

It is older types of tools and technologies, however, which convey the gist of the extensionist idea best. They make it possible for us to do chores that would be harder or even impossible with our regular bodily resources. The hammer, for example, enlarges the "natural" power of our arm. The use of it depends on us initiating a certain force with our arm that is channeled and augmented through the use of the hammer. Spectacles provide sharpened images of our surroundings. The use of them is dependent on our vision, but enhances our "seeing power". Although artifacts like the bicycle, the sewing machine, the stone crusher, the car, and the plane is not as close to our bodily characteristics as the hammer or the spectacles, the use of them involves an expansion of our bodily range, thereby being extensions of our functional body structure. Machines and more complex systems of technologies neither correspond as straightforwardly to the extensionist idea as hand tools, but it is still possible to regard them as extensions in the sense that they are substitutions for work that could be performed by groups of persons; complex technologies collect, focus, and extend several individual performances.

The extensionist idea is neatly summarized in James Feibleman's expression "organ-artifact circuit": "The stove is an external stomach, and cooking is a form of pre-digestion, reducing intractable foods to assimilable form and making possible the consumption of hard fibers which could not otherwise be eaten. Libraries are external memory banks; they contain more information than any single human brain could manage. Computers are external minds; they calculate faster than mathematicians and manipulate abstract thought with great skill and accuracy. Motor cars and airplanes are external muscles; they provide external movement more efficiently than legs" (Feibleman 1979, 399).

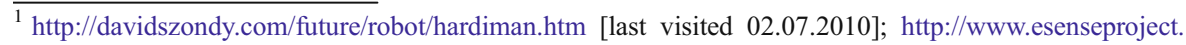
org/thirdEye.html [last visited 02.07.2010]
} 
Conceptualizations similar to the extensionist idea are easily found: Ernst Kapp spoke of technologies as organ projections, while Arnold Gehlen saw technologies as organ substitutions; both thinking of technologies as supplementing the shortcomings of the human physique and transforming our range of bodily action to a range of technical action (Kapp 1877; Gehlen 1980). Alfred J. Lotka coined the term exosomatic organs to describe tools that are external to the body but connect to and augment our endosomatic organs, his term for arms, eyes, ears, and so on (Lotka 1956).

However, the extensionist idea does not just involve body extension; technologies are sometimes regarded to be extensions of the mind, for instance of specific cognitive faculties. Bertram C. Brookes has adopted Lotka's term and claims that computers function as exosomatic brains "whose 'memory' and processing capacities can be increased indefinitely" (Brookes 1975, 47). Gregory Newby concurs, and holds that ideally, an exosomatic memory system should function as a transparent extension of our inherent mnemonic capacities, "so that finding information would seem the same as remembering it to the human user" (Newby 2001, 1029). The only difference, of course, is that as extended with this kind of technology our memory would be immensely larger, just like our arm becomes immensely stronger with a hammer in hand. In much the same vein, we have the extended mind thesis; the claim that cognition sometimes is so dependent on external tools, and adapts so effortlessly to these, that cognition, and perhaps even the mind itself, should be conceptualized to stretch beyond the human brain and body (Clark and Chalmers 1998; Clark 2008; Adams and Aizawa 2010). ${ }^{2}$ Rather more general in its scope, the augmentationist framework in AI-research is a program for the design and development of computers and artificial processing of information as extensions and augmentations of natural human intelligence rather than as a foreign (to brain and mind) kind of intelligence (Engelbart 1962; Skagestad 1993).

A famous use of technologies as mind extension comes from Marshall McLuhan who has argued that while our bodies became extended in the mechanical age, and our central nervous system in the electric technologies from the late nineteenth century and onwards, we are now about to "approach the final phase of the extensions of man - the technological simulation of consciousness, when the creative process of knowing will be collectively and corporately extended to the whole of human society" (McLuhan 2001, 3). Through our technologies, man has become, "an organism that now wears its brain outside his skull and its nerves outside its hide" (McLuhan 2001, 63, 384f). In McLuhan's opinion, our body and our mind are "out there", in the world, through the technologies with which we have colonized it. Through media technologies, which are what occupy McLuhan, humans can connect and perform collectively to reach new levels of competence and enlightenment that would be impossible if we had stayed isolated subjects, i.e., without technology.

Similar ideas to McLuhan's can be found among such internet enthusiasts as the extropians, who claims that the Internet will permit humans to "leave their bodies

\footnotetext{
${ }^{2}$ The external mind thesis is associated with externalism about mental content. Note that the meaning of 'external' in that context - mental content as relying on external phenomena - is actually quite close to the 'internal' approach in the present context, which says that humans and technology co-constitutes each other precisely because they are not external to each other. We hope that this possible conceptual confusion will disappear as we proceed.
} 
behind" and conduct their lives entirely in cyberspace. ${ }^{3}$ The thought here is that the cyber-technology enables us to transcend the limits of our embodied existence, so that we can live, as pure consciousnesses, in a hitherto not seen freedom. Frequently, there is also musings about the possibility of equality and equal distribution of rights and opportunities that appears to be impossible to attain in the physical world. As one enthusiast says, "virtual bullets cannot kill" (Barlow 1998). This semi-Platonic perspective- existence as conscious existence - does not only see cyber technologies as extensions of our mind, but also requires body-extending technologies to take care of all the unpleasant tasks that are required for us to survive, in the bodily sense. We need to be hooked up to the physical world in a way that our technologized body can take care of itself, while we (whatever we can be said to be without bodies) live our lives in cyberspace. According to Barlow, attending to the needs of our body is the reason why our mind has not realized the freedom it has an inherent potential to attain.

Despite appearing as reasonable for certain technologies, the extensionist idea ultimately fails to enlighten us on the nature of our relation to augmentation technologies, or any kind of technology that we trust ourselves to. The main problem with the idea, whether in the form of mind extension or any notion of body or organ extension, is that technologies is seen as extensions of or substitutions for inherent human capabilities; that is, as augmenting or substituting some sort of "natural" bodily and/or cognitive potential. In the extropian case this clearly seen; cyber technologies are taken to emancipate our true nature, enabling it to prosper and unfold; coupling us onto cyberspace does not change us per se; it liberates us. As transparent prolongations of the body or the mind, we attach ourselves to technologies that make no ontological difference to how we perceive or act in the world; the relation is one of strengthening and/or substitution. As such, the extending technology is seen as nothing but a transparent intermediary between the world and us. This is unlucky because it not just gives us (a) an incorrect notion of technology; it also holds (b) a flawed conception of the human-world relation; which implies (c) an inadequate conception of the constitution of a human self. Let us examine these three problematic implications in turn.

\subsection{The Notion of Technology}

The alleged transparency of the relation of extension reinforces the classical position of technological instrumentalism - the disreputed view that technologies are no more than simple means to an end; things that merely, and in a philosophically uninteresting way, connect intentions and effects, without actively contributing to either of them (Heidegger 1977b, 4f; Borgmann 1984, 177; Feenberg 1999, 1). According to technological instrumentalism, when human beings use a shovel to dig a hole in the ground, look into deep space using highly advanced UV telescopes, or read an online article, they interact with the world through technologies that work as mere instruments for their own, pre-given goals, and motivations. Humans perform through the technologies, as it were, to accomplish a deliberate and premeditated change in their social and physical surroundings. For extension technologies, such a

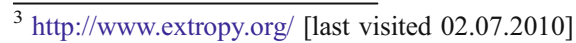


real-world change might be possible only because of the technology-when the change requires bodily and cognitive powers that human beings do not possess in and of themselves, but the technologies will nevertheless be regarded as mere instruments for attaining the change, since they build on abilities and functions that already are a part of human action potential.

The intrinsic instrumentalism of the extensionist idea also implies that the environment in which human action takes place appears the same with or without the technology being involved-sharper, yes (when we were spectacles), closer, yes (when we use a telescope), and frailer, indeed (when we have a sledgehammer in our hands), but that is basically a matter of getting better access to a world that is given independently of technological presence. Consequently, from the viewpoint of extensionism, whatever change results from a technical action-on human beings (new insights from reading the online article) or on the world (a hole in the ground) is primordially understood as an interaction between human and world, and the role of the technology is not considered beyond that of being merely helpful and instrumental. Extensionism, then, implies that both "human beings" (subjects) and the "world" (objects) enter technical actions as pre-defined. From such a viewpoint, technologies only contribute to human action by enlarging and augmenting either human abilities or aspects of the world, without having a significant bearing on either.

Technological instrumentalism has been refuted many times already, and we will not repeat those arguments here in detail. The bottom line is that technological instrumentalism fails to reflect that technologies themselves help to shape action, and the physical and social consequences resulting from it. Some positions point out that specific ideas can be, more or less intentionally, built into the design of the technologies (Winner 1986), while other positions point to the social construction of the impact of technology and the social shaping of conventions for technical actions (Bijker et al. 1985; Oudshoorn and Pinch 2003). In such cases, technologies can be said to embody "scripts" that help to shape both how they are used and what societal consequences they have (Akrich 1992; Oudshoorn forthcoming). This means that, in order to understand a technical action, we have to study the ideas and conventions governing the involved technologies, and the role of the artifacts themselves in the coming about of specific actions, rather than merely focusing on the motives and intentions of technology users.

There is yet another aspect that makes it hard to hold on to technological instrumentalism - an aspect that is highlighted especially in ecological psychology. In a technical action, a technology actually realizes some of its action potential — and this we can call, using a term coined by psychologist James Gibson, the affordance of a technological item (Gibson 1982). ${ }^{4}$ Technologies afford certain ways of being handled, and through that, they afford specific actions.

Affordances, of course, can be traced back to design or to socially governed practices of use, but often the total of potential actions afforded by a technology will

\footnotetext{
${ }^{4}$ Gibson, for most part, discusses what 'affordance' means for a visual psychology. Our use is in a more action-based sense; how an item affords to be handled. This is in line with the more general sense of what it means to afford. Similar expanded utilizations of the expression are easily found. (Norman 1999; Hutchby 2001)
} 
exceed design and convention. ${ }^{5}$ The hammer surely was not designed as a murder weapon but through its materiality, it affords this unhappy usage. SMS, the text function of mobile phones, was not a prioritized function of the development of mobile phones, and was enabled mostly as a by-product of the mobile speech technology (Taylor and Vincent 2005, 77). No one really knew what it could be utilized for, or if it would be utilized (Trosby 2004, 193), and because of the uneasiness of writing messages it was considered primarily as a unidirectional tool; the idea was that the mobile user would only receive messages, for example about incoming voice mails (Taylor and Vincent 2005, 79). However, by affording textual communication between mobile users as well, not just between the mobile company and its clients, this specific affordance took the use of the mobile phone into a surprising trajectory - the average user now receiving more text messages than calls per month. ${ }^{6}$ Furthermore, human beings use specific kinds of technologies, say email instead of a letter or a phone call, precisely because they have some technologyspecific characteristics, like their level of formality, or their required speed of reply. Such characteristics become part of what we communicate when we use them. They are partly, of course, an element of the social meaning that email as a communication medium has taken on, but this social meaning should not be considered independently from what it is possible to attain by using email. In fact, the concept of affordance can be seen as elucidating some of the processes leading up to the stabilization of a specific conventional use (Kiran 2009, 65ff). ${ }^{7}$ To better grasp this non-instrumental aspect of technical action, however, we shall have to turn to the second problematic implication of the extensionist framework, concerning the human-world relation.

\subsection{The Human-World Relation}

As we saw, the extensionist approach depicts human-world relations as transparent; although enhancing aspects of its users or of the world, the technology involved do not add anything philosophically puzzling or interesting to this relation. Nontransparency in this regard means that technologies connect us to the world in ways that could not exist without these technologies. This viewpoint is most comprehensively discussed in Martin Heidegger's well-known "tool-analysis" (Heidegger 1962, §15-18), and similar arguments, developed from different philosophical perspectives, are found in recent philosophy of technology (Ihde 1979, 1990; Verbeek 2005). Heidegger argues that a piece of equipment, through its zuhandenheit, its readiness-to-hand, constitutes a specific relation between the particular item and the item's environment. This relation has a structure of what

\footnotetext{
${ }_{5}^{5}$ Don Ihde points to a similar phenomenon that he calls 'multistability', which alludes to the shifting conventions for use of artifacts in different cultural contexts. Relating this to our terminology, we can say that items are multistable because they afford several technical actions. (Ihde 1990:144ff)

${ }^{6}$ Not to mention the impact the character-limit of text messages (160 characters) has had, and probably will continue to have, on language.

${ }^{7}$ An affordance should not, however, be seen as denoting something inherent in an item. Instead, it is something that is revealed in the interaction of an item and a particular user; an affordance is not reducible to either properties or interpretations. As mentioned, potential use of an item often transcends designed and conventional use, and in addition, inventive use, such as using the hammer as a murder weapon, should not be understood as a mere personal/mental interpretation, but as something that is also enabled and constrained by the item itself.
} 
Heidegger calls "in-order-to": it involves a referring that we simply cannot grasp in analyzing an item outside of its context of use. The referring serves a dual purpose: it displays what serves as context for the item, and through doing so; the item in turn is constituted as a tool within that context: "Equipment... always is in terms of its belonging to other equipment: ink-stand, pen, ink, paper, blotting pad, table, lamp, furniture, windows, doors, room. These 'things' never show themselves proximally as they are for themselves... Out of this the 'arrangement' emerges, and it is in this that any 'individual' item of equipment shows itself' (Heidegger 1962, 97).

Although the context has primacy for Heidegger, human beings only come to know this context through the handling of the tools, through what Heidegger calls the items' "specific thingly character", a concept that roughly corresponds to affordance. This implies that a piece of equipment influences the world to appear for us in a manner that is in accordance with its affordances. A claw hammer, to use a very tired example, affords rock hard hits and pulling things, which points it toward a context that includes nails and spikes, items that in turn afford hitting or pulling. The nails and the spikes stick out from a background, the world, because of the hammer. Without a certain piece of equipment, we would not perceive the world, or act in it, in the way that we do. In other words, through a technical action, the world is disclosed in a manner that is partly due to the involved tools; some things are accentuated and stand out, others glide into the background, because of how tools hook us up to its context. Tools, and technologies, in Heideggerian terms, involve a revealing-concealing structure; they constitute the relations between human beings and their world.

Ihde's notion of magnification-reduction structure suggests a similar impact on our perceptions and actions from technology. In technical actions, Ihde says, technologies that augment and strengthen our capabilities will simultaneously reduce or weaken other aspects (Ihde 1979, 9). Scratching the surface of a blackboard with a dentist's probe produces a tactile experience of the blackboard that is quite different from the one we would have if we had touched it with our finger directly. Through the probe, we can feel scratches and marks in the surface that we cannot feel with the bare finger. The finger, on the other hand, would have given us experiences of a certain temperature and of the old chalk dust that usually covers the surface of blackboards, but leave the small irregularities overlooked. In this case, "[a] microscopic presence is amplified through the probe thus extending my experience of the board to a level of discernment previously unnoted" (Ihde 1979, 9). Binoculars make distant phenomena more distinct. At the same time, other phenomena become less detailed or out of sight - things that are close and to the side disappear. Most people gesticulate when they speak on the phone-why? Clearly, the phone enables us to speak to persons not present, but it is unable to communicate the bodily gestures we often depend on in face-to-face conversation. The telephone does retain intonation, though. This, however, is lost in other forms of communication technologies, such as the written letter and in e-mails, which affords communicating in a different way from the phone or face-to-face, but have their own reductions.

Using technologies means that we are in our surroundings in specific ways, relating ourselves to the aspects of the world that technologies help to accentuate and stand out. Technologies co-shape the appearance of the world; we do not just see a world, the world appears to us in certain ways: technologies structure and organize the world. Using technologies for sight means that we see our surroundings 
differently, using a hearing aid means that we hear things differently. The hammer and the ax, and the bulldozer for that matter, mean that we act in our environment differently. Our activities are different due to the technologies, not because we act can differently in an already perceived world, but because we perceive the world itself differently.

Regarding technologies as extending mediators that offer a transparent, albeit augmented, link between the world and us implies that we use technologies to reach already defined goals. However, the above implies that through making us perceive our surroundings in specific ways, technologies co-shape our ability to even catch a glimpse of such goals, and therefore also set them as goals. In other words, we cannot employ technologies as extensions of our body to obtain foreseen goals unless these goals already were disclosed by the technology. Technologies are approached as enabling actions; not something that we ourselves would have been able to do had we had harder hands, stronger vision, et cetera, but something that enables us to relate to the world in manner not hitherto known. Technologies aid our intentionality, our manner of being in the world; they are part of us, but not body parts. The tool, or the entity taken as a tool, is taken as a tool not just because it affords us to do something we ourselves are not able to do, but because it affords us to perceive and act in the world in a different manner. The revealing-concealing aspect of technologies, the co-shaping of the man-world relation, is lost in the extensionist idea.

\subsection{Constitution of Subjectivity}

The impact of technologies on how we find ourselves in the world becomes more conspicuous when we shift the perspective from actual technical actions to technologies' impact through potential actions. Technologies do not just suddenly appear before our eyes, and then connect us to the world in accordance with their "specific thingly character". We always already apprehend the world in line with what we can possibly do in it, and these possibilities are very much related to the technological presence in our lifeworld. In other words, we do not perceive the technologically structured world primarily because of the technologies we have in our hands, but because we know that technologies present us with opportunities; technologies embody potential. Potentiality rather than actuality points us to the goals that we, individually or collectively, are able to set.

Furthermore, this perspective allows us to see the third flaw of the extensionist idea; it fails to disclose the impact of technology on the constitution of human existence. In line with Heidegger's analysis, technology can be said to play a role at the level of the temporal dimension of human existence. Human existence is not something that just exists in a now, or in a past leading up to a now; it always anticipates the future. Any kind of planning, whether it is an arrangement for one's days of retirement, the summer holiday next year, or going to the grocery store to get some cheese, presupposes that we recognize ourselves as existing in a future, and, furthermore, as having certain possibilities to do something with our lives in this future. In other words, an integral part of how our present lives are conducted is due to how we think about, hope for, and anticipate our future existence. Said differently, human existence takes shape in terms of possibilities, in terms of what it might become. And this is where technological affordances play a central role. Human 
possibilities, in Heidegger's analysis, are fundamentally related to those phenomena that we find around us; human existence can only "take shape" in relation to that which makes up our lifeworld. This includes not only other subjects and the social world, but also the world of things (Heidegger 1962, 79ff).

Interestingly, from this perspective there is a sense of technological presence also when technologies are not in actual use. An example here is the way many people depend on their mobile phones. The influence of the cell phone exceeds that of being handy whenever we need it. Its availability reflects back to how avid mobile users understand their own identity and potential. Others may have the same relation to their car or motorcycle. Think of the disorientation when such dependent-upontechnologies disappear for use; the helplessness, and the sheer effort it takes just to get through the day. Human beings have come to depend on their lifeworld to be structured and organized by the presence of technologies. Note that this does not require the actual realization of the possibilities afforded by technologies; technologies help to constitute the structure of the lifeworld through both actual and potential affordances. ${ }^{8}$ Also regarding what people take to be their nonpossibilities, technological presence in this sense is important. Many elderly people are convinced that they will never be able to learn the intricacies of online banking, so they sees this way of dealing with their economy as a non-possibility for them personally, while still recognize it as a possibility for other people. Consequently, they see themselves as persons who are confined to the old fashion way of banking. The availability of technologies reflects human possibilities right back at them, in a here-and-now perspective and in a more long-term sense, as thoroughly related to what they regard themselves to be.

\section{Trust Beyond Extensionism: Two Examples}

The notion of technologies as extensions of the human being, to conclude, is inadequate. Technologies do much more than merely extending and strengthening the abilities and capacities that human beings already possess, or highlighting and enlarging specific aspects of the world. Technologies always connect human beings in specific ways to the world and in doing so they help to shape both the character of human existence and of the world in which it plays itself out. What technologies afford us; how they connect us to the world and what world they connect us to, points to a fundamentally non-transparent human-technology relation. Technologies do not extend human beings, but rather help to constitute them.

The implications of this criticism of technological extensionism for understanding the relations between technology and trust can be illustrated best by discussing two exemplary technological domains. A first example is the field of telemonitoring devices in healthcare. Telemonitoring technologies can enable chronic patients to live at home, rather than in hospital, potentially allowing patients to lead a better and more meaningful life in minimizing the impact of the disease on their overall lives.

\footnotetext{
${ }^{8}$ This point is interesting in relation to those potential affordances that go unrecognized. Such potentiality underlines that the structuring of the lifeworld to a certain degree is "out of our hands", but we cannot take the discussion here (but see Kiran 2009 for an extended argument for this).
} 
Such devices can check, for example, people's heartbeat and heart rhythm, blood pressure, muscle tension, et cetera. Telemonitoring technologies have an obvious connection to trust: patients want to be able to rely on them, and they are often experienced as extensions of the body.

A good example of such technologies is Myotel. This device monitors the muscle activity of patients with permanent whiplash and people with work-related neck and shoulder complaints. The main device in this system is a Body Area Network (BAN) suit that uses on-the-skin electrodes to measure muscle activity, especially in the trapezius muscle, during everyday activities. Whenever the system finds that the value for relative rest time is too low, the patient receives an audio signal, short regular vibrations from the BAN, and a visual feedback on a PDA. The patient should now do some personalized exercises as agreed upon in consultation with the physical therapist prior to being given the BAN in order to relax the muscles. The PDA also transmits information about these occurrences to a Myotel Service Centre where the patient's therapist gains access to the data. Based on this information the therapist and the patient have regular telephone conversations about the progress of the treatment (Jones et al. 2008).

At first sight, it might seem quite plausible to see such devices as extensions of the body, simply making information available about people's physical condition. And from such an 'external' conceptualization of the human-technology relation the principle issue of trust here would concern the risks involved in using this technology. Does the technology indeed provide accurate information, does wearing the BAN not have any detrimental side effects, can the collected information be misused, et cetera. But, once used, such devices do not merely operate as extensions; they have a profound impact on people's existence. For example, they imply an important shift in responsibilities for one's health condition: patients themselves now get involved much deeper in taking responsibility for their own healthcare. Although one has to wear the BAN throughout the day, the actual time the complaint consumes is reduced; one does not have to travel to the therapist regularly, and one only needs to perform the exercises when required rather than based on a time schedule. Also, the device has an impact on people's self-image and their experience of being ill. Chronic pain can now be understood as relating to one's behavior, and for those with permanent neck- and shoulder complaints, this device opens a different directedness toward one's future, making it possible to participate in everyday life in a way that would not be possible otherwise. Rather than being external, the relations between patients and telemonitoring devices appears to be internal: one's subjectivity takes shape in relation to the technology, instead of merely being extended by it.

A second example to show the necessity of a broader conception of trust beyond extensionism is prosthetic technologies: technologies that strengthen, replace, or enhance parts of the human body, like brain implants and limb prostheses. These technologies, as well, at first sight might seem to be extensions of the body or even of the mind. They replace or add power to specific elements of the human being, sometimes even crossing the boundary between 'therapy' and 'enhancement', making it possible to "improve" the human being rather than restoring an original condition. But at the same time, such technologies do much more. Instead of merely extending the human subject, they have the potential to change it. 
In sports, for example, fierce discussions have been going on about how to deal with prostheses that could make people perform better and therefore problematize central notions like fairness and authenticity of achievement (Savulescu 2006). And in neurology, a rapidly growing field concerns neuromodulation technologies. The technology of deep brain stimulation, for example, makes it possible to stimulate or deactivate specific parts of the brain. This can dramatically improve the situation of patients suffering from, among others, Parkinson's disease, but it actually does much more. Severe personality changes can occur, for example, and the very possibility to be literally "switched on and off" - the device can be operated with a remote control-has important implications for people's self-understanding and their relation to their environment (Leentjens et al. 2004).

Also in these cases, issues of trust could be phrased in terms of 'external' relations between technology and humanity, focusing on the risks involved in using these prostheses, or on the quality of the ways they fulfil their function. But given their deep influence on people's existence, issues of trust entail much more. Although approaching these technologies merely as 'external' devices that might involve risks harbors important issues that needs to be addressed, this approach ultimately fails to take into account how deeply interwoven they are with human existence, and how deeply they are affecting the quality of people's lives. Trusting prostheses and deep brain implants also implies trusting aspects of oneself to technologies. If one's subjectivity is affected by the impact of technologies, trusting technology becomes a deliberate act of confidence. In order to address this other dimension of trust, in the next section we will elaborate a broader, and more 'internally' oriented, conceptualization of trust.

\section{Trusting Ourselves to Technology}

How to develop an account of trust that is based on a conceptualization of the relations between humans and technology as 'internal'? Conceptualizations of trust, as we saw, often presuppose a fundamental distinction between human beings on the one hand and technologies on the other-if there would not be a way in which technology could affect human beings, or in which human beings would need to rely on technology, there could not be a relation of trust, it seems. Yet, by taking the intricate connections between humans and technology as a starting point, rather than as a situation of extension or of risk, we can develop an alternative conception of trust.

For doing this, we will take Martin Heidegger's philosophical analysis of technology as a starting point again, albeit in a somewhat unorthodox way. In the introduction to this article, we pointed to two seemingly contradicting elements in Heidegger's philosophy of technology: his ideas about tools as being reliable on the one hand, highlighting the importance of trust in the relations between humans and technologies; and his ideas about technology being the highest danger on the other hand, highlighting that, for Heidegger, technology ultimately embodies a specific, empowering relation to reality that seems to rule out alternative relations. These two elements in Heidegger's analysis of the relations between humans and technology can now be reinterpreted in a rather unruly way in order to rethink the notion of trust. 
First of all, in line with Heidegger's tool analysis, as discussed above, the notion of reliability should not be seen as indicating an external or instrumental relation of use. Rather, the concept of reliability indicates how things can make the world accessible for human beings; how they can connect human beings to the world, making possible engaged practices and experiences. When being reliable, a tool does not merely function smoothly; it also forms the basis of new relations between its users and their environment. Rather than merely facilitating human beings, they help to shape what it means to be a human being, by opening new ways of being-in-theworld in which both human beings and the world are constituted in specific ways.

Secondly, Heidegger's notion of technology as "the ultimate danger" needs to be reconsidered in the light of contemporary analyses of the relations between humans and technologies. French philosopher Bernard Stiegler, for example, argues for the "originary technicity" of human beings. Rather than seeing technologies as a threat to what it means to be a human being, they constitute humanity (Stiegler 1998). This statement needs to be understood at the most basic anthropological level: because of the mere fact that human beings have the ability to use technologies, they have been able to develop the way they did in human evolution. The Heideggerian analysis of technology as the most basic framework in which human beings find themselves, if they want it or not, should not be seen as a threat to humanity, but as a source of it. The Gestell, as Heidegger calls the technological framework of contemporary life, should not be seen as a form of alienation, but an element of the human condition.

This analysis seems to make an ethical evaluation of technology highly complicated, though. If human beings are the products of technology rather than its users, we seem to have given up all ethical space that was so abundantly available in technological instrumentalism and extensionism. The 'external' conceptualization of the human-technology relation made possible precisely that which the internal conceptualization seems to give up: the very possibility to assess the quality of the impact that technologies have on human existence. There is a third way, though, between a mere instrumentalist conceptualization of technology and a radical fusion of both. Conceptualizing the relations between humans and technologies as internal does not necessarily imply that human beings need to be seen as helpless victims of technology. The technological condition of human existence can also be understood as a task. Rather than seeing technology as alienating, we should approach it as a starting point for shaping human existence. In explicitly developing relations to technologies and their mediating roles, human beings give shape to their technologically mediated existence.

Counter intuitive as it may seem, such an approach to the relations between human beings and technologies can even be further articulated in line with various elements of Heidegger's approach to technology and human existence. Inspired by Steven Dorrestijn's reading of Michel Foucault's work on the "care of the self" as a starting point for an ethics of technology (Dorrestijn 2006), we propose to understand the active shaping of one's technologically mediated existence as a form of "care". And for Heidegger, care is a central element of human existence: human beings are beings who are concerned about their own being. Their existence takes shape in careful involvements with human beings and things. Current insights in the deep intertwinement of humanity and technology, and in the technologically 
mediated character of human existence, make it possible to add a reflexive, or second-order, dimension to this care-structure of human existence. Human existence takes shape in "careful" relations with other human beings and things; but human beings can also take care of the character of these relations themselves. Rather than merely being "implied" in a technological system, they can be aware of the ways in which technologies help to give shape to their existence, and be actively involved in this constitution of the self.

Consequently, we can say that involving oneself with technologies is, at the same time, a form of self-care. We can see this in the Myotel case. Telemonitoring devices like this have an important impact on how people experience their disease, and how they live their lives with it. When using the Myotel, successful treatment requires the patient to take responsibility for tasks that otherwise would be the responsibility of healthcare professionals. Moreover, sensations of pain are directly linked to actions one can undertake oneself to prevent the pain from getting worse or even occurring. The Myotel system thus offers patients a new framework to interpret their own behavior and experiences, and to give shape to their lives with pain.

It would be too narrow to limit the meaning of trust in this context to issues of reliability. Malfunctioning of the Myotel system, obviously, would be undesirable; but the most relevant aspects of trust actually occur when it is functioning properly. The decision to share one's treatment process with a Myotel system implies trusting oneself to this device. And this trusting-to can have an active character. It is not necessarily a blind surrender to technology; people can actively shape their subjectivity in interaction with the impacts of the Myotel system. They become different patients, different partners, different employees, different parents, et cetera, depending on how they deal with the frameworks for action and interpretation the device implicitly and explicitly gives them. In such a way, they take responsibility for the ways in which they are affected by the technology. Of course, telemonitoring technologies can be risky-when they give false or unreliable information, for example, or when they break down. And, indeed, such technologies can be seen as extensions: because people can "expand" themselves with such devices, they can live at home, rather than in a hospital. But, at the same time, these technologies have important impacts on people's existence, and allow for careful appropriation and "self-care".

An interesting example in the context of prosthetics is the technology of deep brain stimulation (DBS). This technology uses a neuro-implant to activate or deactivate specific parts of the brain. Deep brain stimulation is used for a wide variety of diseases, ranging from Parkinson's disease to depression and obsessivecompulsory disorder. Several years ago, a specific case was described in the Dutch medical journal Tijdschrift voor Geneeskunde that illustrates quite dramatically what self-care can entail in the context of prosthetics. The case concerned a patient suffering from Parkinson's disease, whose condition improved markedly after applying deep brain stimulation (Leentjens et al. 2004). But while the symptoms of his disease were mitigated, his behavior changed as well. He developed uninhibited forms of behavior that he had not shown before. For instance, he started an affair with a married woman and bought her a second house; he bought several cars; got involved in a number of traffic accidents; and eventually he lost his driver's license.

The man had no awareness of this behavior change, until the DBS was switched off. At that moment, however, his Parkinson's symptoms returned with such severity 
that he became entirely dependent and confined to his bed. He had to choose between a bedridden life with Parkinson's disease, and a manic life with DBS. And this caused a complicated situation of trust. Trusting himself to DBS for this man implied having to choose between two important aspects of his selfhood. Eventually he chose- -with the DBS switched off-to be taken into a psychiatric ward, where the DBS could be switched on so that the symptoms of his disease would be mitigated, but where, at the same time, he would be protected against himself in case of manic episodes.

This form of "self-care" can be seen as the ultimate embodiment of what Heidegger called "releasement" (Gelassenheit), albeit in a radically different way than Heidegger himself envisaged it (Heidegger 1977c). For Heidegger, releasement was the only possible answer to the manipulative, technological way of thinking. Any attempt to develop an alternative to manipulative thinking, according to Heidegger, would necessarily be a form of manipulation itself-except for the attitude of releasement. This attitude consists in saying both "yes" and "no" to technology, accepting technology as unavoidable but deciding not to get too deeply involved with it. By elaborating the concept of care in terms of caring for one's mediated existence, though, it becomes possible to reinterpret the concept of releasement in a less technophobic direction.

In this reinterpretation, "saying both yes and no to technology" does not imply a minimization of one's involvement with technology, but rather the development of explicit engagement with it. It does not consist in avoiding technological mediations, but in recognizing them, and in getting involved in the ways they affect our existence. Instead of keeping a safe distance to technology, this form of self-care embodies a secondary form of distance: it entails both being involved with technology and taking a stance toward this involvement.

Releasement, in this interpretation, comes down to taking care of one's technologically mediated existence, rather than staying away from technology as much as possible or simply believing it is a transparent extension. Instead of suspicion and reliance, here we encounter a third manifestation of trust, which could be indicated as confidence. From this manifestation of trust, human beings deliberately and actively trust themselves to technology. Rather than being risky or useful, technology is approached here as trustworthy. While recognizing the technological condition of human existence - and, therefore, thinking in terms of 'internal' relations between human beings and technologies - caring for one's existence does not imply a blind surrender to technology; instead, it comes down to taking responsibility for the ways in which one's existence is impacted by technology.

This "third way" in the relations between trust and technology requires confidence in both technology and humanity. On the one hand, it requires an approach to technology as mediating human existence, rather than threatening it and putting it at risk, or merely facilitating it. And on the other hand, it requires an approach to humanity as being fundamentally interwoven with technology, rather than being authentic and autonomous. Moreover, in order to be able to trust oneself to technology, two specific conditions need to be met. First, the technology in question needs to leave room to develop an explicit relation to its mediating role, rather than being dominating or overpowering. And second, human beings need to have the ability to "read" the mediating roles of the technology, and the skills to "appropriate" it in specific ways. 


\section{Conclusion}

Trust is a central dimension in the relation between human beings and technologies. The various manifestations of trust reflect the various shapes this relation can have. In many discourses about technology, the relation between human beings and technologies is conceptualized as an external relation: a relation between pre-given entities that can have an impact on each other but that do not mutually constitute each other. From this perspective, relations of trust can vary between reliance, as is present for instance in technological extensionism, and distrust, as in various precautionary approaches in ethics that focus on technological risks.

This conceptualization of trust in relation to risk, however, imposes upon us a false dilemma of how to deal ethically with technologies: as if ethics were only about accepting them or rejecting them. Once we develop a more internal account of the relations between human beings and technologies, we begin to see that in order to gain trust in technologies, we must first trust ourselves to technologies. This, however, does not imply subjecting ourselves uncritically to them, but rather recognizing that technologies help to constitute us as subjects, and that we can get actively involved in these processes of mediation and subject constitution. Rather than giving up freedom, this is a way to create freedom. Rather than being free from constraints, this approach understands freedom as developing a free relation to the forces that help to shape our selves. Trust here has the character of confidence: trusting oneself to technology.

Because of the close relations between human beings and technologies, using technologies implies putting oneself at stake. Human beings co-shape themselves through the relations they have with technology, as we illustrated by discussing how people can shape their lives by dealing actively with the mediating effects of telemonitoring technologies and prostheses. In order to justify the internal character of the relations between human beings and technologies, the main concern for the ethics of technology should be how to take responsibility for the quality of technological mediations, and of our ways of living with these mediations.

Acknowledgments This article was made possible by NWO, Netherlands Organization for Scientific Research (Programmes: Socially Responsible Innovation, project "Telecare at Home" and Innovational Research Incentive, project "Technology and the Limits of Humanity"). The authors would like to thank Ciano Aydin, Lucie Dalibert, Steven Dorrestijn, René Munnik, and Petran Kockelkoren for their valuable comments on earlier versions of this article.

Open Access This article is distributed under the terms of the Creative Commons Attribution Noncommercial License which permits any noncommercial use, distribution, and reproduction in any medium, provided the original author(s) and source are credited.

\section{References}

Adams, F., \& Aizawa, K. (2010). The bounds of cognition. Wiley-Blackwell.

Akrich, M. (1992). The de-scriptation of technical objects. In Bijker \& Law (Eds.), Shaping technology/ building society. Studies in sociotechnical change (pp. 205-224). MIT Press.

Asveld, L., \& Roeser, S. (Eds.) (2008). The ethics of technological risk. Earthscan Publications Ltd.

Barlow, J.P. (1998). Leaving the physical world. Paper: The Conference on HyperNetworking, Oita, Japan. http://w2.eff.org/Misc/Publications/John_Perry_Barlow/HTML/leaving_the_physical_world.html. Accessed February 7, 2010. 
Bijker, W. J., Hughes, T. P., \& Pinch, T. (Eds.) (1985). The social construction of technological systems. MIT Press.

Borgmann, A. (1984). Technology and the character of contemporary life. The University of Chicago Press.

Brookes, B. C. (1975). The fundamental problem of information science. In: Horsnell (Ed.) Informatics 2, 42-49. Aslib.

Clark, A. (2003). Natural-born cyborgs. Minds, technologies, and the future of human intelligence. Oxford University Press.

Clark, A. (2008): Supersizing the mind. Embodiment, action, and cognitive extension. Oxford University Press.

Clark, A., \& Chalmers, D. J. (1998). The extended mind. Analysis, 58(1), 7-19.

Dorrestijn, S. (2006). Michel Foucault et l'éthique des techniques: Le cas de la RFID. Nanterre: Université Paris X (Mémoire).

Ellul, J. (1964). The technological society. Vintage Books.

Engelbart, D. C. (1962). Augmenting human intellect: A conceptual framework. In: Stanford Research Institute, Summary Report, Project No. 3578. http://www.liquidinformation.org/engelbart/62_paper full.pdf, last visited: 02.07.2010.

Feenberg, A. (1999). Questioning technology. Routledge.

Feibleman, J. K. (1979). Technology and human nature. Southwestern Journal of Philosophy, 10(1), 35-41.

Fukuyama, F. (2002). Our posthuman future: Consequences of the biotechnology revolution. Farrar, Straus and Giroux.

Gehlen, A. (1980). Man in the age of technology. Columbia University Press.

Gibson, J. J. (1982). Reasons for realism. Selected essays of James J. Gibson. Lawrence Erlbaum.

Habermas, J. (2003). The future of human nature (Trans. H. Beister, M. Pensky \& W. Rehg). Polity.

Hansson, S. O. (2009). Risk and safety in technology. In Meijers (Ed.), Handbook of the philosophy of science, vol. 9: Philosophy of technology and engineering sciences (pp. 1069-1102). Elsevier.

Heidegger, M. (1962). Being and time. Basil Blackwell.

Heidegger, M. (1977a). The origin of the work of art. In: Basic writings (Trans. D. F. Krell). New York: Harper \& Row.

Heidegger, M. (1977b). The question concerning technology. In: The question concerning technology and other essays (Trans. W. Lovitt). New York: Harper \& Row.

Heidegger, M. (1977c). The turning. In: The question concerning technology and other essays (Trans. W. Lovitt). New York: Harper \& Row.

Hutchby, I. (2001). Technologies, texts and affordances. Sociology, 35(2), 441-456.

Ihde, D. (1979). Technics and Praxis. Reidel.

Ihde, D. (1990). Technology and the lifeworld. From Garden to Earth. Indiana University Press.

Jaspers, K. (1959). Man in the modern age (Trans. Eden and Cedar Paul). Routledge \& Kegan Paul Ltd. Jonas, H. (1984). The imperative of responsibility. Chicago: University of Chicago Press.

Jones, V. M., Huis in't Veld, R., Tonis, T., Bults, R. B., van Beijnum, B., Widya, I., Vollenbroek-Hutten, M., Hermens, H. (2008). Biosignal and context monitoring: Distributed multimedia applications of body area networks in healthcare. In 2008 IEEE 10th International Workshop on Multimedia Signal Processing, MMSP.

Kapp, E. (1877). Grundlinien Einer Philosophie Der Tecknik. Zur Entstehungsgeschichte Der Cultur Aus Neuen Gesichtspunkten. Braunscheig: G. Westermann.

Kiran, A. H. (2009). The primacy of action. Technological co-constitution of practical space. Doctoral Thesis Norwegian University of Science and Technology 2009:105.

Latour, B. (1993). We have never been modern (Trans. C. Porter). Cambridge, Harvard University Press.

Leentjens, A. F. G., Verhey, F. R. J., Visser-Vandewalle, V., \& Temel, Y. (2004). Manipuleerbare wilsbekwaamheid: een ethisch probleem bij elektrostimulatie van de nucleus subthalamicus voor ernstige ziekte van Parkinson. Nederlands Tijdschrift voor Geneeskunde, 148, 1394-1398.

Lotka, A. J. (1956). Elements of mathematical biology. Dover.

McLuhan, M. (2001): Understanding media. The extensions of a man. Routledge.

Newby, G. (2001). Cognitive space and information space. Journal of the American Society for Information Science and Technology, 52(12), 1026-1048.

Norman, D. A. (1999). Affordances, conventions, and design. Interactions, 6(3), 38-42.

Oudshoorn, N. (forthcoming). Who cares? Telecare technologies and the transformation of healthcare. MIT Press, forthcoming.

Oudshoorn, N., \& Pinch, T. (Eds.) (2003). How users matter. The co-construction of users and technology. MIT Press. 
Savulescu, J. (2006). Justice, enhancement and fairness. In Bainbridge \& Roco (Eds.), Progress in convergence: Technologies for human wellbeing (pp. 321-338). New York Academy of Sciences.

Skagestad, P. (1993). Thinking with machines: Intelligence augmentation, evolutionary epistemology, and semiotic. Journal of Social and Evolutionary Systems, 16(2), 157-180.

Stiegler, B. (1998). Technics and time, 1. The fault of Epimetheus. Stanford University Press.

Taylor, A. S., \& Vincent, J. (2005). A history of SMS. In Hamill \& Lasen (Eds.), Mobile world: Past, present and future. Springer.

Trosby, F. (2004). SMS, the strange duckling of GSM. In Telektronikk 3.2004.

Verbeek, P. P. (2005). What things do. Philosophical reflections on technology, agency, and design. Pennsylvania State University Press.

Winner, L. (1986). The whale and the reactor. A search for limits in an age of high technology. University of Chicago Press. 